\title{
Bearing Stress at Failure of Double-Lap Hybrid Joints in Woven Fabric Kenaf Fiber Composite Plates under Quasi-static Loading
}

\author{
Sim Yee Lee ${ }^{1, *}$, and Hilton Ahmad ${ }^{1}$ \\ ${ }^{1}$ Faculty of Civil and Environmental Engineering, Universiti Tun Hussein Onn Malaysia, 86400 Parit \\ Raja, Batu Pahat, Johor, Malaysia
}

\begin{abstract}
The present paper is focused on the bearing stress at failure of double-lap woven fabric kenaf fiber reinforced polymer (KFRP) hybrid bonded-bolted joints in experimental frameworks. The effects of different normalized plate width (plate width/hole diameter, $W / d$ ), lay-up types and bolt loads were incorporated in current study as specified in testing series. Generally, hybrid joint coupons separated within adhesive layer prior to net-tension failure or bearing/net-tension failure. The bearing stress at failure increased as $W / d$ ratio increment, critical $W / d$ is given as four and three in clamped and finger tight condition respectively. Lay-up types present insignificant effect to bearing stress at failure due to low volume fiber fraction in kenaf fiber composites. Combination of thicker and clamped conditions plate demonstrated greater bearing stress than equivalent finger-tight (FT) conditions due to higher load transferred from friction, as expected.
\end{abstract}

\section{Introduction}

The awareness of renewable plant for massive productions is progressively developed in recent years due to evolution in biotechnology development. Renewable natural fibers able to replace commercially synthetic fiber in production of natural composite materials with medium and low bearing load applications [1]. Generally, natural fiber has greater properties compared to synthetic fiber i.e., higher specific strength [2], low carbon dioxide $\left(\mathrm{CO}_{2}\right)$ emissions, biodegradable, good thermal and acoustic insulation. Recent studies investigates the suitability of biodegradable composite materials using natural fibers such as flax, bamboo, pineapple, silk, sisal, jute, kenaf, and ramie for manufacturing sectors. Kenaf fibers is one of the important source of natural fiber extracted from bast and core fibers, previous study reported that the tensile and flexural strength of kenaf reinforced polylactic acid (PLA) composites were approximately $223 \mathrm{MPa}$ and $254 \mathrm{MPa}$ respectively with $70 \%$ fiber fraction. It had proved that kenaf fiber showed higher strength compared to other natural fibers in reinforcing PLA [3].

* Corresponding author: simsim1019@hotmail.com 
Structures components require joining techniques to assemble different parts and connection is the weakest point when subjected to applied load. Hybrid adhesively bondedbolted joint (hybrid joint) method is a lap joint technique combines advantages in conventional bolted joints and adhesively bonded joints. Hybrid joints able to decrease high peel stress near plate edges and subsequently increased static strength [4]. The presence of fasteners in hybrid joints assists the continuous operation of the joining structure despite the occurrence of adhesive failure. Observations by Bois et al. [5] found that three types of prominent failure modes in hybrid joints, i.e. net-tension failure, adhesive joint failure and bearing failure. However, currently there is no standard for testing method/set-up available as reference for hybrid joints. More recent studies have proved that hybrid joints demonstrated greater static strength than bolted joints or adhesively bonded joints alone. Franco et al. [6] had proved that under pre-tension bolt decreased maximum shear and peel stress and therefore increased the static strength of hybrid double-lap with joining GFRPaluminium plates, approximately similar to the total tensile strength in respective bolted joints and bonded joints. Nabil et al. [7] had investigated the strength on bolted joint, adhesively bonded joint and hybrid joint of HexPly M18/1/G939 carbon fiber/epoxy laminates and found that the bolts in hybrid joint relieved exhibited peels stress to delay crack formation within adhesive layer.

However, the research works on kenaf fiber reinforced polymer is relatively limited. It has excellent engineering behaviour such as impact and fatigue resistance due to ability of the crimp to absorb energy as crack developed. Further investigation on these composite types need to be examined for structures applicability, especially in joining structures. Lee et al. [8] showed that failure load increased substantially with $W / d$ in single-lap hybrid joints on woven fabric kenaf fiber composite plates. Current study broadens the study on bearing stress at failure of hybrid joint double-lap woven fabric KFRP with various parameters. The testing series of current work was designed and mechanical machines were carried out as elaborated in next section.

\section{Experimental methodologies}

\subsection{Testing coupons preparation}

The KFRP composite panels were prepared by stacking the plain weave kenaf fiber layer and combined with resin system using hand lay-up fabrication technique under compression. The kenaf fiber yarns have 276 tex (weight in grams of $1000 \mathrm{~m}$ of the tow), weaved using rigid plain handloom with tow density of 4 end per $\mathrm{cm}$ in warp direction and 4 pick per $\mathrm{cm}$ in weft direction. The term ends and picks describe the number of warp tows and weft tows, respectively, per unit length. Matrix binder system was prepared by mixing thermoset epoxy resin (SP84) and hardener (SP76) with ratio 2:1. Plain weave kenaf fiber layer was placed on aluminium mould and smeared the binder system uniformly with extra care to avoid entrapped voids and bubble formation. These steps were repeated accordingly to the desired stacking sequence and fiber orientations, at least twenty-four hours curing period were allowed to set under the room temperature prior to demolding. Table 1 showed the testing variables tested (lay-up types, end-distance $(e)$ to hole diameter ratio, normalized $W / d$ and bolt loads) with detailed diagram for one lay-up is given in Fig. 1. 
Table 1. Double-lap hybrid joint testing coupon series.

\begin{tabular}{|c|c|c|c|c|}
\hline Laminate & $\begin{array}{c}\text { Lay-up } \\
\text { Orientation }\end{array}$ & $\boldsymbol{e} / \boldsymbol{d}$ & $\boldsymbol{W} / \boldsymbol{d}$ & Clamp-up torque \\
\hline PX2 & $(0 / 90)_{\mathrm{S}}$ & 6 & $2,3,4,5$ & $\mathrm{FT}, 5 \mathrm{Nm}$ \\
\hline $\mathrm{PX} 4$ & $(0 / 90)_{2 \mathrm{~S}}$ & 6 & $2,3,4,5$ & $\mathrm{FT}, 5 \mathrm{Nm}$ \\
\hline $\mathrm{PS} 2$ & $( \pm 45)_{\mathrm{S}}$ & 4 & $2,3,4,5$ & $\mathrm{FT}, 5 \mathrm{Nm}$ \\
\hline $\mathrm{PQ} 4$ & $(0 / 90 / \pm 45)_{\mathrm{S}}$ & 4 & $2,3,4,5$ & $\mathrm{FT}, 5 \mathrm{Nm}$ \\
\hline
\end{tabular}

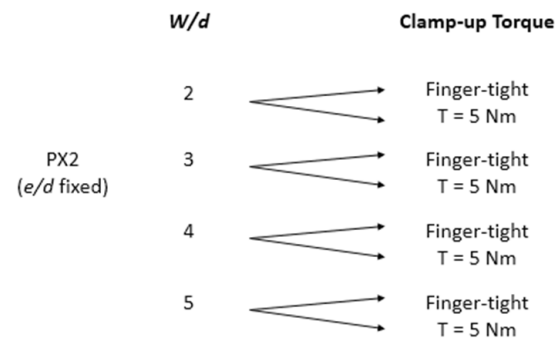

Fig. 1. Testing series carried out on one of the laminate type, PX2

Karakuzu et al. [9] concluded that e/d ratio was fixed to 6 for cross-ply lay-up and 4 for quasi-isotropic lay-up to eliminate shear-out failure. The hole diameter, $d$ used in current work was fixed to $5 \mathrm{~mm}$ and drilled by using high-speed drilling bits to reduce hole edge defects. Normalised plate width, $W / d$ was ranging between 2 to 5 . The fabricated composite panels were sectioned according to the desired testing coupon sizes by using a cooling diamond saw. An adhesive layer $(\sim 0.1 \mathrm{~mm}$ thick) was applied within the plate overlap region and a M5 size fastening system was then installed under finger-tight/clamped condition by using KTC Digital Torque Wrench GEK 030-C3A immediately prior to mechanical testing to eliminate the bolt relaxation effect. A double-lap hybrid joint configuration ready for mechanical testing is shown in Fig. 2. Finger-tight (FT) condition $(\sim 0.5 \mathrm{Nm})$ was used as the worst case scenario and clamp-up torque with $5 \mathrm{Nm}$ was frequently used in composite joint design [10].

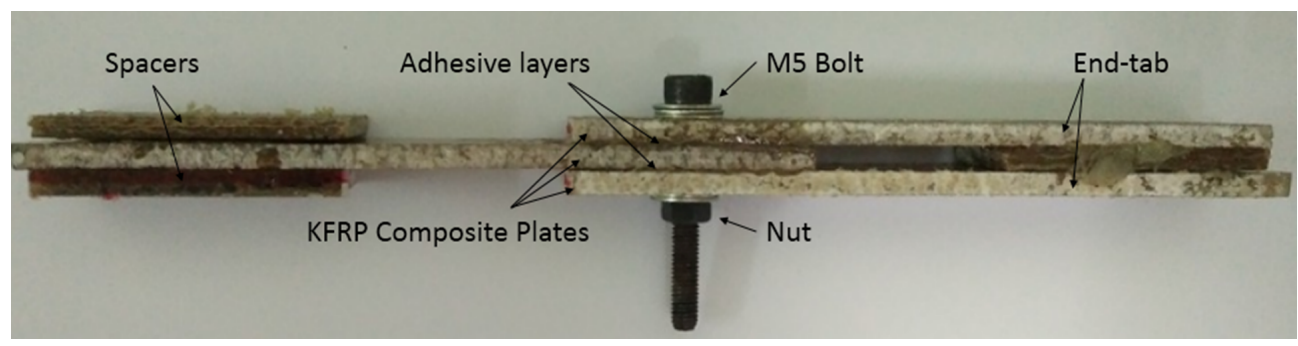

Fig. 2. Photograph of PX4 hybrid double-lap joint.

\subsection{Mechanical testing}

At least three set of testing joints in each joint designation series were tested and bearing stress at failure values were averaged. ASTM Standard D3039B [11] was referred for the mechanical testing set-up. The quasi-static tests were conducted by using universal testing machine SHIMAZU AG-I with a constant cross-head speed of $0.5 \mathrm{~mm} / \mathrm{min}$ and $10 \mathrm{kN}$ of load cell capacity. The end-tabs were prepared at the coupon edge adhered with aluminium 
strip prior to testing to avoid slippage during mechanical testing. Spacers with same adjacent plate thickness were prepared to avoid the primary bending as shown in Fig. 2. Bearing stress at failure, $\sigma_{b}$ was obtained by using following expression, where $P_{\max }$ is the maximum fracture load at failure, $d$ is diameter of hole and $t$ is plate thickness.

$$
\sigma_{\mathrm{b}}=\frac{\mathrm{P}_{\max }}{\mathrm{dt}}
$$

\section{Results and discussion}

\subsection{Load-displacement profile}

The load-displacement curves were consistent in hybrid joints tested. A Representative load-displacement graph is shown in Fig. 3. From the load-displacement graph shown in Fig. 3, it is clearly presented that there are few stages prior to the ultimate load., as obtained from data-logger, i.e., adhesive failure, bearing contact and plate failure. Plate failure showed net-tension failure in smaller $W / d$ coupons and bearing/net-tension failure occurred in larger $W / d$ coupons as shown in Fig. 4. At early stage, it showed a linear elastic behaviour before the adhesive failure. As applied load increased, the peel stress near the edges of shear-lap was increased and cohesive cracks initiated and propagated which is also known as cohesive failure. Similar findings by Lee et al. [12] where they observed adhesive layer was failed initially, followed by mechanical fastened failure in hybrid joint. Next, the curve showed a constant line where friction load transferred from bolt to joining plates. As the applied load exceeded the bolt load applied $\left(\mathrm{P}>\mathrm{P}_{\text {bolt }}\right)$, the composite plate were slipped and the bearing contact between bore hole and bolt shaft took place within bearing area. Subsequently, the applied load is borne by individual joining plates until final failure.

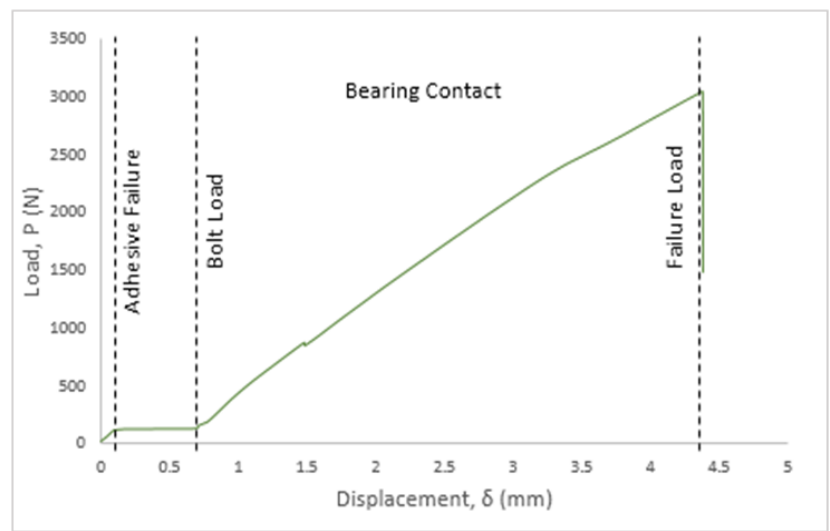

Fig. 3. Load-displacement profile for PQ4 lay-up with finger-tight condition $(W / d=3)$.

\subsection{Bearing stress at failure with variation of normalized $W / d$, lay-up and bolt load}

Photograph of PQ4 coupons under finger-tight conditions with normalized $W / d$ is shown in Fig. 4. It is clearly observed that all testing coupons were failed in net-tension mode. Consistent trend with single-lap non-crimp CFRP hybrid joint was reported by Kelly et al. [13], critical $W / d$ (transition from net-tension to bearing failure) is given as three. 
Compared to catastrophic nature in net-tension failure, bearing failure demonstrated more progressive failure type. Although bearing failure is preferable, but net-tension mode is unavoidable due to geometry constraint and bolt load applied. Current work suggests the critical $W / d$ in woven fabric KFRP is larger than five. As expected, bearing stress at failure increased with $W / d$ ratio due to larger unloaded region along the net-tension plane.

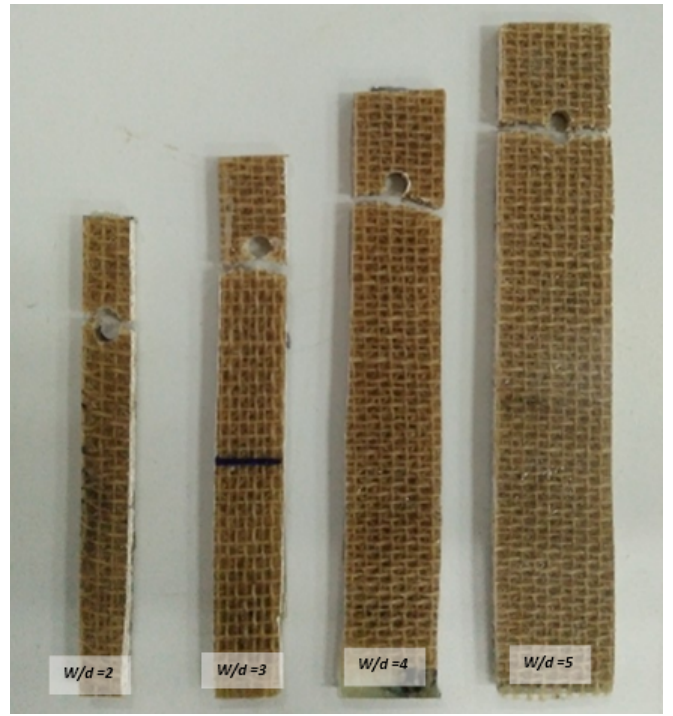

Fig. 4. Photograph of tested coupons for PQ4 lay-up with different $W / d$.

As shown in Fig. 5, both lay-up types showed insignificant effect in bearing stress at failure due to similar volume fiber fraction, $V_{f}$ of woven fabric kenaf fiber, which is approximately $17 \%$. Although more volume of $0^{\circ}$ fiber orientation in cross-ply lay-up, but due to low volume fracture fraction demonstrated insignificant effect to ultimate bearing stress. Therefore, close values of bearing stress at failures with respective to normalized $W / d$ in both lay-up types is perhaps not surprising. On the other hands, thicker plate (PX4 and PQ4) showed higher bearing stress at failure than equivalent thinner plates (PX2 and PS2). Generally, thicker coupon is efficient to transfer more load through plate thickness to give higher peak load. Bearing stress increased with plate thickness, consistent with the findings by Gordon Kelly et al. [13].
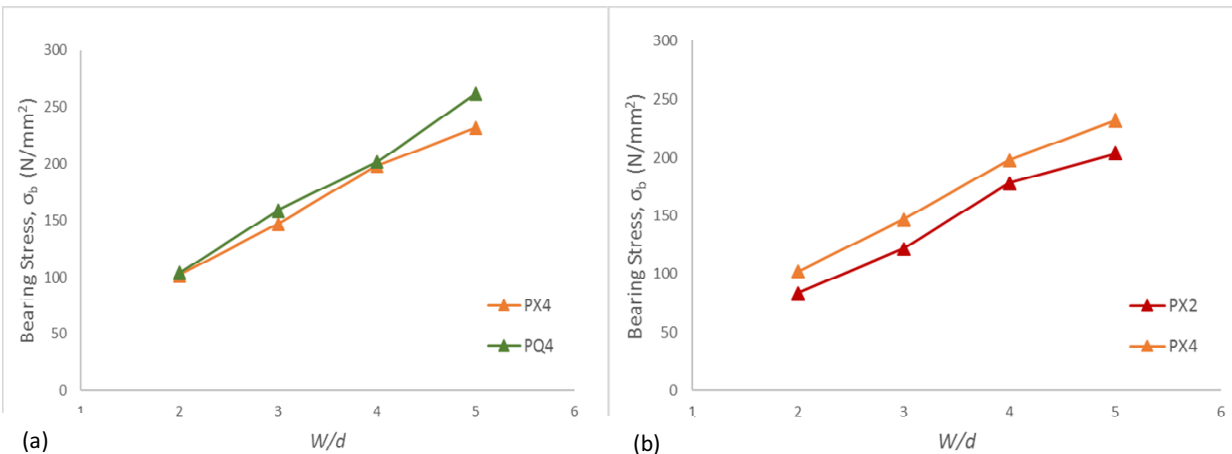

Fig. 5. Effect of (a) lay-up stacking (b) plate thickness on bearing stress at failure with clamped condition. 
In application of bolt load, introduction of pre-tension load in bolt able to produce compression in out-of-plane between joining plates. Clamped condition showed more uniform stress distribution along the overlap region and helps to alleviate the peel stress as a result of stress concentration as reported by Franco et al. [6]. When applied load is less than bolt load $\left(P<P_{\text {bolt }}\right)$, the load transfer was concentrated within contact region near the bolt head and nut. The amount of applied load, $P$ to surpass the $P_{\text {bolt }}$ is smaller under fingertight condition than under clamped condition, as expected. Thereafter, slippage occurred at the shear plane when $\mathrm{P}>\mathrm{P}_{\text {bolt }}$, both plates were subsequently separated as a result of cohesive cracks and plate splitting along the adhesive layer parallel to applied load. Finally, applied load was borne by the individual plate. Similar findings were reported by Kim, J.-S. et al. [14]. Fig. 6 showed the increased bearing stress at failure as a function of bolt load as the frictional load transfer by clamped bolt increased.

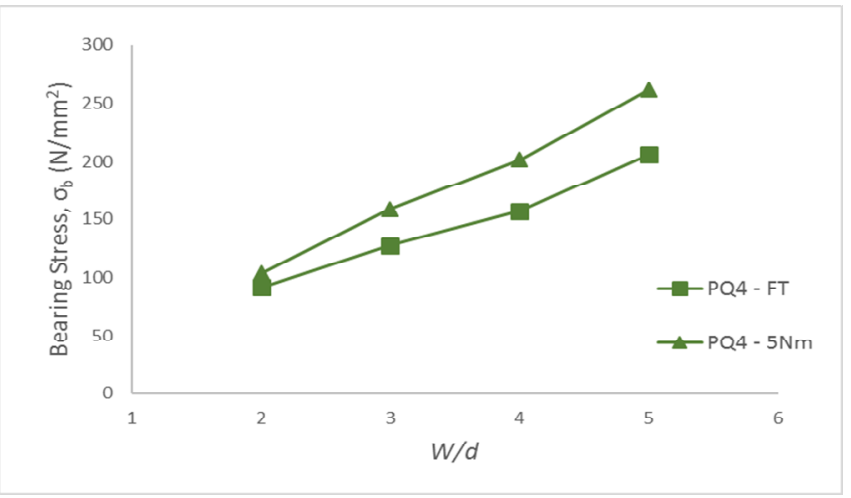

Fig. 6. Effect of bolt load on bearing stress at failure for PS2 and PQ4.

\section{Conclusions}

All testing coupons exhibited final failure modes in net-tension suggesting critical $W / d$ is more than five. Larger normalized plate width, $W / d$ showed higher bearing stress at failure due to larger unloaded region along the net-tension plane with larger plate width. Thicker plates and clamped condition able to transfer more load through the plate thickness that gives higher bearing stress at failure. Double-lap joint does not exhibited secondary bending, therefore experimental framework on single-lap joint need to be carried out to broaden the scope of current work.

The authors gratefully acknowledge Universiti Tun Hussein Onn Malaysia (UTHM) and Research Grant Scheme under IGSP U245. This paper was partly sponsored by the Centre for Graduate Studies UTHM.

\section{References}

[1] O. Faruk, A. K. Bledzki, H.-P. Fink, and M. Sain, Biocomposites reinforced with natural fibers: 2000 - 2010, Progress in Polymer Science, 37(11), 1552-1596, (2012)

[2] H. M. Akil, M. F. Omar, A. a. M. Mazuki, S. Safiee, Z. a. M. Ishak and A. Abu Bakar, Kenaf fiber reinforced composites: A review, Material and Design, 32(8), 4107-4121, (2011)

[3] S. Ochi, Mechanical properties of kenaf fibers and kenaf/PLA composites, Mechanics of Materials, 40(4-5), 446-452, (2008) 
[4] G. Marannano and B. Zuccarello, Numerical experimental analysis of hybrid double lap aluminum-CFRP joints, Composites. Part B Engineering, 71, 28-39, (2015)

[5] C. Bois, H. Wargnier, J.-C. Wahl and E. L. Goff, An analytical model for the strength prediction of hybrid (bolted/bonded) composite joints, Composite Structures, 97, 252260, (2013)

[6] G.D. Franco and B. Zuccarello. Analysis and optimization of hybrid double lap aluminum-GFRP joints, Composite Structures, 116, 682-693, (2014)

[7] M.C. Nabil, J. Wang, K.C. Wing and P. Chang, Static and fatigue testing bolted, bonded and hybrid step lap joints of thick carbon fibre/epoxy laminates used on aircraft structures, Composite Structures, 142, 96-106, (2016)

[8] S.Y. Lee and H. Ahmad, Experimental strength of single-lap hybrid joints on woven fabric kenaf fiber composites under quasi static condition, The 3rd International Conference on Civil and Environmental Engineering for Sustainability, MATEC Web of Conferences, 47, Article No. 02003, (2016)

[9] R. Karakuzu, T. Gulem and B. M. Icten, Failure analysis of woven laminated glassvinylester composites with pin-loaded hole, Composite Structures, 72, 27-32, (2006)

[10] H. Ahmad, A.D. Crocombe and P.A. Smith, Strength prediction in CFRP woven laminate bolted double-lap joints under quasi-static loading using XFEM, Composites: Part A Applied Science and Manufacturing, 56, 192-202, (2014)

[11] ASTM D3039/D3039M, Standard test method for tensile properties of polymer matrix composite materials, ASTM International, West Conshohocken, United States, (2008)

[12] Y.H. Lee, D.W. Lim, J.H. Choi and M.K. Yoon, Failure load evaluation and prediction of hybrid composite double lap joints, Composite Structures., 92, 2916-2926, (2010)

[13] G. Kelly and S. Hallstrom, Bearing strength of carbon fibre/epoxy laminates: effects of bolt-hole clearance, Composites: Part B, 35, 331-343, (2004)

[14] J.S. Kim, J.Y. Lim and W.G. Lee, Joining performance evaluation of different types of gep224 glass/epoxy-to-az31b magnesium alloy single lap joints, Int. J. Precision Engineering and Manufacturing, 16(6), 1135-1140, (2015) 